\title{
MADERAS DE CATALUÑA PARA LA MARINA DE LA ILUSTRACIÓN. FUENTES PARA EL ESTUDIO DE LOS BOSQUES CATALANES Y SU RELACIÓN CON LA CONSTRUCCIÓN NAVAL EN EL SIGLO XVIII
}

\author{
Vicente Ruiz García \\ UNED Jaén, España \\ vicruiz@jaen.uned.es
}

\begin{abstract}
RESUMEN: Desde la Edad Media las maderas de los bosques de Cataluña habían sido empleadas para la industria naval del Principado, especialmente para la construcción de galeras en las Atarazanas de Barcelona. Sin embargo, fue sobre todo a partir del siglo XVIII cuando la explotación forestal de los bosques de Cataluña tendría un gran desarrollo a raíz de la política de reconstrucción de la Marina Española impulsada por la nueva dinastía de los Borbones. Con este fin, los pinos de Tortosa, los robles de Girona o las coníferas del Pirineo fueron conducidas por vía fluvial a través del Ebro y sus afluentes hasta llegar a la costa catalana. De allí las maderas serían trasladadas por mar hasta Cartagena, el arsenal que más empleo la materia prima de los bosques de Cataluña para la construcción y reparación de los buques de la Armada, al menos hasta 1793.
\end{abstract}

Palabras clave: arsenal de Cartagena, maderas, construcción naval, historia naval, Cataluña siglo XVIII.

\section{WOODS OF CATALONIA FOR THE NAVY OF ENLIGHTENMENT. SOURCES FOR THE STUDY OF CATALAN FORESTS AND THEIR RELATIONSHIP WITH SHIPBUILDING IN THE 18TH CENTURY}

ABSTRACT: Since the Middle Ages the woods of the forests of Catalonia had been used for the naval industry of the Principality, especially for the construction of galleys in the Atarazanas of Barcelona. However, it was mainly from the 18th century when the forestry exploitation of the forests of Catalonia would have a great development because of the policy of reconstruction of the Spanish Navy promoted by the new dynasty of the Bourbons. To this end, the pines of Tortosa, the oaks of 
Girona or the conifers of the Pyrenees were transported by river via the Ebro and its tributaries to reach the Catalan coast. From there the wood would be moved by sea to Cartagena, the arsenal that used the raw material of the forests of Catalonia for the construction and repair of ships, of the Spanish Navy, at least until 1793.

Keywords: arsenal of Cartagena, wood, shipbuilding, naval history, Catalonia XVIII century.

Recibido: 30 de noviembre de 2018

Aceptado: 4 de enero de 2019

\section{Introducción}

A mediados del siglo XVIII los Montes de Cataluña mantuvieron un régimen jurídico especial a raíz de la implantación de la Ordenanza para la conservación y aumento de los montes de Marina promulgada por Fernando VI el 31 de enero de 1748 que asumía el control y administración por parte de la Marina de un espacio cuya superficie arbolada se extendía desde los Pirineos hasta el Delta del Ebro incluyendo las sierras del interior, los ríos navegables y los bosques del litoral hasta una distancia de veinticinco leguas más allá de la costa catalana. Con este nuevo régimen administrativo el Estado Absolutista de los Borbones pretendía adquirir la madera que generaban estos bosques, materia prima esencial que sería empleada para la construcción naval en los arsenales de la Corona, especialmente en el de Cartagena. Fue entonces cuando a mediados de siglo comenzó una explotación exhaustiva y sistemática de pinos y robles con destino a la construcción y carena de buques de la Armada aunque ya desde la Edad Media la Marina había empleado habitualmente los bosques catalanes para el surtimiento de astilleros, dentro y fuera de la Corona de Aragón.

Definitivamente este artículo es una aproximación a la historia de los bosques de Cataluña y su proyección marítima partiendo de un análisis de las fuentes para su estudio con las que podemos descubrir la repercusión de sus maderas en la construcción naval de los arsenales de Marina durante el siglo XVIII.

\section{Objetivos}

- Reconstruir y analizar la historia de las Provincias Marítimas del Principado de Cataluña a partir de la interpretación crítica de los trabajos científicos y divulgativos publicados hasta la fecha que de una u otra forma se han acercado a la cuestión aportando nuevas fuentes documentales primarias para un mejor conocimiento de los hechos.

- Cubrir el vacío historiográfico en relación con el destino de las maderas de Cataluña y su empleo en la construcción naval con el fin de descubrir su proyección y su verdadera importancia en el contexto de la Marina Española de la Ilustración. 
- Identificar y estudiar otros arsenales distintos al de Cartagena donde también se emplearon las maderas de Cataluña.

- Ofrecer una propuesta rigurosa y científica para renovar, explicar, aclarar discusiones y explorar nuevas líneas de investigación para contribuir al mejor conocimiento de lo que fueron los Montes de Cataluña y su proyección marítima durante el siglo XVIII.

- Recapitular y analizar de manera crítica lo ya escrito en cuanto al régimen administrativo, el proceso de la explotación forestal, el transporte de madera o las resistencias locales, revisando nuevas fuentes que nos puedan aportar más datos.

\section{Fuentes secundarias para la investigación de las maderas de Cataluña y la Marina de la Ilustración. Una revisión bibliográfica}

Aunque tenemos referencias de la segunda mitad de siglo ${ }^{1}$, fue sobre todo hasta mediados del setecientos cuando los pinos de Tortosa se convirtieron en los más habituales para la elaboración de arboladuras, lo que demuestra la importancia de las maderas catalanas en la construcción naval durante este periodo tal y como queda reflejado ya en 1724 en Teoría y práctica de Comercio y Marina, la gran obra del economista Gerónimo de Uztáriz donde proponía la creación de un astillero en los Alfaques:

Para un buen astillero en los Alfaques, nos ofrecen también los montes de Tortosa y otros de Cataluña y Aragón buenos robles, que en cantidad considerable necesitan para la fábrica de los buques en que el consumo es mucho mayor que el de las arboladuras, y tablazón, que se traen de las alturas de los Pirineos $(. . .)^{2}$

Iván Valdez-Bubnov señala que esta propuesta era una defensa de la construcción tradicional por asiento en Cataluña, en contra del proyecto centralizador de Patiño y los partidarios de Cádiz para instalar un astillero. ${ }^{3}$

A pesar de las referencias tan tempranas a las bondades de los bosques de Cataluña y la empleabilidad de sus maderas en la construcción naval, no tene-

1. Archivo del Arsenal de Cartagena (en adelante ANC), Libro de Acuerdos de la Junta Económica, Tomo 13, fol. 157; Perchas y masteleros de Tortosa. Junta celebrada el 28 de agosto de 1787.

2. Uztáriz, G., Theorica, y Practica de Comercio y Marina, en diferentes discursos, y calificados exemplares que, con especificas providencias, se procuran adaptar a la Monarquía Española, para su prompta restauración, beneficio universal, y mayor fortaleza contra los émulos de la Real Corona. Madrid 1757, p. 129. Aunque esta obra de Uztáriz salió a la luz en 1724 en una limitadísima tirada hemos empleado la edición de 1757 mucho más cuidada que la primera.

3. Valdez-Bubnov, I., Poder naval y modernización del Estado: política de construcción naval española (siglos XVI-XVIII). México 2011, p. 211. 
mos trabajos publicados que estudien a fondo la contribución de las maderas de Cataluña a la creación de la Marina de la Ilustración. No obstante, contamos con interesantes estudios que estrechan el espacio geográfico y temporal limitándose a determinadas áreas o comarcas catalanas. Es el caso del estudio que hacen Marcel Pujol Hamelink y Pablo de la Fuente de Pablo que analizan la contribución de los pinos de Tortosa y de los robles y encinas en Requesens, para la construcción de navíos para la orden de Malta en el arsenal de Tolón a principios del siglo XVIII ${ }^{4}$ o el trabajo de Miquel Ángel Fumanal i Pagès, Ester Galimany Bustos y Mónica López Prat que se ciñe a la comarca del Alt Urgel. ${ }^{5}$

Mayor tratamiento, aunque insistimos, insuficiente, ha tenido el trasporte fluvial por los ríos catalanes de las maderas con destino a los arsenales de la Marina. Ya lo hizo el propio Uztáriz cuando narraba cómo los troncos eran trasladados desde los montes a través de almadías navegando por el río Ebro hasta los Alfaques. Consideraba que todas estas operaciones de trasporte, a pesar de ser arduas, terminaban mereciendo la pena pues, no había que desembolsar grandes cantidades de dinero para adquirirlos en el Báltico y desde allí se distribuían a los diferentes astilleros de la Monarquía, redundando todo ello en beneficio público:

(...) los referidos árboles, y demás maderas en el caudaloso Ebro, se conducen por él siempre atados, hasta los Alfaques de Tortosa, de donde se transportan, y distribuyen en diversos Puertos del Mediterráneo, y del Océano, para el servicio de los bajeles de Guerra, y Galeras de su Majestad, ni los Navíos del Comercio pendientes, de si estos géneros vienen, o dejan de venir de las Provincias del Norte, ya por la oposición de los temporales, ya como queda dicho, por la de las guerras, o intereses encontrados de las Potencias, como sucedía muchas veces por lo pasado; excusándose también por este motivo, la perdida de la gran cantidad de dinero, que nos sacaban por el valor, y tráfico, así de los Mástiles, y Tablazón (... ${ }^{6}$

Más recientemente y sobre el transporte fluvial y el papel de los madereros destacan los trabajos de Joan Maluquer de Motes $^{7}$, Ángel de Portet, ${ }^{8}$ Severino Pallaruelo ${ }^{9}$ y Ezequiel Giménez Rodríguez quien se centra en la zona de Pallars-Urgell. Este último autor afirma que el bosque catalán se vio castigado de forma brutal por la tala de árboles

4. Hamelink, M.P.; De Pablo, P.D.L.F., "Fusta dels boscos de Requesens per a la construcció de navilis de l'orde de Malta (1702-1704)" Annals de l'Institut d'Estudis Empordanesos, 2015, vol. 46, pp. 413-428.

5. Fumanal i Pagès, M. À.; Galimany Bustos, E.; López Prat, M., "El rètol de Fígols... o la marina de Carles III al cor del Pirineu" 2015.

6. Uztáriz, G., Theorica, y Practica ... p. 169.

7. Maluquer de Motes, J., "L'explotació del bosq i el transport de la fusta (els raiers)" L'Avenc, 34, 36-43.

8. Portet, À., "Els raiers: el transport fluvial de la fusta del Pirineu a la Mediterrània." Plecs d'història local, 1996, $\mathrm{n}^{\circ}$ 62, pp. 968-971.

9. Pallaruelo, S., Navateros. Zaragoza 2008. 
destinados a la construcción naval de la Marina ${ }^{10}$. Una postura que pone en entredicho Vicent Ferrer Pérez que desmitifica el papel asignado a la Marina como destructora y aniquiladora de las masas arbóreas de la región levantina durante el siglo XVIII ya que, según este autor, los bosques presentaban, en general, un estado lamentable desde hacía mucho tiempo, como consecuencia de la acción humana, y la cantidad de madera empleada en la zona era muy limitada si la comparamos con otras actividades como la construcción civil o la obtención de carbón vegetal. No obstante, este autor, aunque hace alguna referencia a las maderas catalanas, se centra en el territorio del reino de Valencia por lo que quizás no sea extrapolable para Cataluña. ${ }^{11}$

Además del Reino de Valencia, la mayor parte de las Provincias Marítimas que se extendieron por los dominios de la Monarquía durante el siglo XVIII atesoran interesantes trabajos de investigación en torno a la explotación forestal que la Marina ejerció en sus montes. Especialmente por su número destacan los que estudian la Cornisa Cantábrica $^{12}$ la Sierra de Segura ${ }^{13}$ o América ${ }^{14}$. Por el contrario, Cataluña no cuenta

10. Giménez Rodríguez, E., "L’Explotació forestal al Pallars durant el segle XVIII: els raiers." Drassana: revista del Museu Marítim, 1995, n 4, pp. 16-21.

11. Ferrer Pérez, V. "Els boscos valencians i la construcció naval en la segona meitat del segle XVIII". Cuadernos de geografía, 2001, Número 69-70: 23-52. Del mismo autor ver Los montes valencianos al final del Antiguo Régimen: política forestal y aprovechamientos de la cubierta vegetal. Tesis Doctoral. Universidad de Valencia. Sobre el mismo tema centrado en Valencia De La Croix, J. Memoria premiada que contiene la indicación de los montes del Reyno de Valencia: clase, utilidad, uso y abundancia o escasez de sus maderas: ríos y carreteras que facilitan su extracción: causas de la decadencia de los bosques de este Reyno, medios de evitarla y de asegurar su permanencia, Junta Pública de la Real Sociedad Económica de Amigos del País de Valencia celebrada el día 9 de diciembre de 1800. Valencia: Benito Monfort, 1801, pp. 163-267.

12. Entre otros Liaño, C.D.; García Cordón, J. "La corona y los pueblos en la explotación de los montes de Cantabria: deforestación y gestión del bosque en la segunda mitad del siglo XVIII". Cuadernos de la Sociedad Española de Ciencias Forestales, 2003, n 16, p. 215-220; Oyarbide Odriazola, M.L. "El bosque de Irati y el transporte de las maderas hasta los Reales Arsenales de Marina (Segunda mitad del Siglo XVIII)." Boletín de la Real Sociedad Bascongada de Amigos del País, 2008, vol. 64, ${ }^{\circ}$ 2, pp. 845-863; Iturrate, J. "Elaboración de remos de mar y extracción de madera para navíos reales en los montes de Gorbea (Alava), País Vasco. Documentos varios (ss. XVII-XVIII)." Kobie. Antropología cultural, 2001, no 10, pp. 117-128; Berriochoa Azcárate, P. "El bosque de Gipuzkoa entre los siglos XVIII y XX: deforestación y cambio de especies." Estudios Rurales, 2016, vol. 6, nº 11.

13. Valgan como ejemplos Cruz Aguilar, E., "La Provincia Marítima de Segura de la Sierra." Separata publicada en el boletín no 107 del IEGG. Dip. Prov. De Jáen; López Arandía, M.A., "Maderas del rey. Aprovechamientos madereros en la Provincia Marítima de Segura de la Sierra." Araque Jiménez. E. (coord.): Aprovechamientos madereros en los montes jiennenses (ss. XIII-XX), Jaén 2012. pp. 13-78; Merino Navarro, J.P. "La Marina en los montes de Segura, 1734-1800", Córdoba, I Congreso de Historia de Andalucía, 1978; Rodríguez Tauste, S. "La Provincia Marítima de Segura de la Sierra. Siglos XVIII-XIX" Araque Jiménez. E. (coord.): Aprovechamientos madereros en los montes jiennenses (ss. XIII-XX), Jaén 2012. pp. 79-123; Ruiz García, V. De Segura a Trafalgar, Torredonjimeno, El Olivo editorial, 2010; La Provincia Marítima de Segura y la Marina de la llustración. La contribución de las maderas de Segura de la Sierra a la construcción naval del siglo XVIII. Instituto de Estudios Giennenses-Diputación Provincial de Jaén, Jaén, 2019.

14. Entre otros Flores Clair, E., "Un mar de intereses, la producción de pertrechos navales en Nueva España, siglo XVIII". América Latina en la Historia Económica. Revista de Investiga- 
con ningún trabajo de investigación que analice de manera integral la explotación forestal de sus bosques y el empleo de sus maderas en los arsenales de la Armada durante el siglo XVIII. No obstante existen referencias en obras generales como en el trabajo de Juan Piqueras Haba y Carme Sanchís Deusa sobre el transporte fluvial de madera en España donde se detiene en la Región Maderera de los Pirineos y explica el transporte por el río Ebro y sus afluentes. ${ }^{15}$ También se ofrecen detalles en el artículo de Alfredo José Martínez González sobre las masas forestales para las Armadas donde el autor recuerda los montes del Principado de Cataluña y con especial interés de nuevo los de Tortosa, un área donde se promovió la conservación y aumento de sus pinos, útiles en arboladura pero también la elaboración de betunes de "pez y alquitrán", tal y como regulaba el capítulo 78 de las Ordenanzas de Marina. Una práctica que generó frecuentes fricciones entre la población y las instituciones de la Corona encargadas de la construcción naval. ${ }^{16}$ Este autor profundiza sobre el tema en Las Superintendencias de Montes y Plantíos (1574-1748), tesis doctoral donde desarrolla el papel de estas instituciones creadas con el fin de regular la gestión y explotación de los bosques para el surtimiento de los astilleros y arsenales de Marina durante los siglos XVI, XVII y XVIII. En la obra describe las necesidades madereras de los astilleros y arsenales frente a las de las poblaciones locales lo que dio origen a conflictos jurisdiccionales sobre los recursos silvícolas. Además, en esta monografía también hay sitio para los montes de Cataluña en el capítulo dedicado a los conservadores de montes en aquel Principado y en el epígrafe donde analiza las diferencias jurisdiccionales en las distintas regiones. ${ }^{17}$

Pero sin duda alguna y hasta el día de hoy destaca el libro La Armada Española en el siglo XVIII, de Patricio Merino Navarro basado en su tesis doctoral que fue editada en Madrid por la Fundación Universitaria Española en 1981 y que, quizás, sea uno de los mejores y más completos trabajos sobre la organización, administración y funcionamiento de la Armada durante el Siglo de las Luces, especialmente en lo concerniente a sus arsenales. ${ }^{18}$ Es precisamente en

ción, 2009, n 31; Funes Monzote, R. "Conocimiento y explotación de los bosques cubanos por la Marina real española en el último tercio del siglo XVIII." Expediciones, exploraciones y viajeros en el Caribe, 2003.

15. Piqueras Haba, J.; Sanchis Deusa, M.C., La conducción fluvial de maderas en España. Godella (Valencia) 2015, pp. 68-88; y "El transporte fluvial de madera en España" Geografía histórica, 2001.

16. Martínez González, A. J., "Masas forestales para las Armadas: las áreas jurisdiccionales de montes y plantíos (siglos XVI-XVIII)" Naveg@ mérica, nº 14, 2015.

17. Martínez González, A. J., Las Superintendencias de Montes y Plantíos (1574-1748). Derecho y política forestal para las armadas en la Edad Moderna. Valencia 2015, pp. 125-173, 252-273.

18. Merino Navarro, J.P., La Armada española en el siglo XVIII. Madrid 1981. Parte de este trabajo fue incluido en una obra de conjunto bajo el título "La Armada en el siglo XVIII" Las Fuerzas Armadas Españolas. Historia Institucional y Social. Madrid: Alhambra. Tomo II, pp. 85-147. 
el abastecimiento de materia prima para estos complejos fabriles donde el autor se detiene en el estudio de los montes de Cataluña con un importante acopio de fuentes documentales procedentes del Archivo General de Simancas, del Archivo General de Marina "Álvaro de Bazán" del Viso del Marqués e incluso de otros archivos locales. Con esta sólida base documental, Merino Navarro se acerca a las Provincias Marítimas del Principado de Cataluña con un enfoque más global, no como sujeto sino como objeto dentro de las áreas de abastecimiento de pertrechos que la Armada empleó en el siglo XVIII. Una década después, con este mismo enfoque pero de una manera más superficial, Gaspar de Aranda y Antón volvió a referirse de manera muy breve a los montes de Cataluña desde la óptica de la ciencia forestal y de la construcción naval en Los bosques flotantes. Historia de un roble del siglo XVIII, publicado por el ICONA en $1990^{19}$ y diez años más tarde en La carpintería y la Industria naval del siglo XVIII, donde establece un periodo de cortas de madera en los Montes de Cataluña entre 1726 y $1780 .^{20}$

Es evidente que la explotación forestal ejercida por la Marina debió influir de alguna manera en la deforestación del territorio aunque, quizás, es cuanto menos discutible su grado de responsabilidad si lo comparamos con otros agentes y causas. En este sentido ya los contemporáneos debatieron en torno al tema tal y como refleja Josep María-Tomás Grau i Pujol y Poser Puig i Tàrrech en un artículo que trata sobre el debate en torno al bosque durante la Ilustración en Cataluña a partir de varios textos escritos por botánicos contemporáneos, donde se analizan las diferentes concepciones del bosque catalán en este período, subrayando las causas que determinaban la deforestación y apuntando básicamente hacia dos factores: la legislación vigente sobre bosques y la expansión de los cultivos. En cuanto a la legislación, las ordenanzas forestales fueron rechazadas frontalmente siendo criticadas con rotundidad su arbitrariedad, su rigor, su ineficacia y, sobre todo, su excesivo intervencionismo y poco respeto por el derecho a la propiedad privada. ${ }^{21}$ Un argumento que ayudó a desatar el conflicto entre agricultores y pastores contra el Estado Absolutista por el uso del bosque, hecho que no es exclusivo de Cataluña y que ha quedado ampliamente recogido en numerosas fuentes primarias.

19. De este autor también es preciso hacer referencia sobre "Relaciones documentales de los bosques y montes marítimos peninsulares en los archivos históricos españoles durante el siglo XVIII y comienzo del XIX". Revista Ecología. no 17. 2003. pp. 359-379; y "Los bosques y los montes españoles en los archivos históricos de la Marina Española". Revista de Historia Naval. $n^{\circ} 21$, pp. 13-48.

20. Aranda y Antón, G. La carpintería y la industria naval en el sig/o XVIII. Madrid, Instituto de Historia y Cultura Naval (Cuadernos monográficos del I. H. C. N., nº 33), 1999.

21. Grau Josep M. T., y Puig i Tàrrech, R. L'Aprofitament del bosc a l'època moderna: la Conca de Barberà, s. XVIII, Barcelona 1990. 
Con un enfoque parecido y con este punto de vista forestal no debemos dejar pasar de largo la obra del doctor Erich Bauer Manderscheid, y su clásico Los Montes de España en la Historia, publicado en 1980 por el Ministerio de Agricultura ${ }^{22}$. Una obra de altura aunque discutida y que está siendo objeto de revisión pero que, no obstante, ha servido y sirve de fuente a otros autores que se acercan a la evolución del paisaje de la Península Ibérica a lo largo de la historia y que en sus páginas incluye a Cataluña y en algún caso no olvida el destino de las maderas para la construcción naval. Por ejemplo cuando hace referencia a una carta escrita en 1744 por Antonio Gartini que informaba al marqués de la Ensenada de las dificultades que tenía para obtener árboles para la construcción de dos galeras en Barcelona, pues "los bosques pertenecientes a seculares están deteriorados" subrayando los problemas para efectuar talas en los bosques en poder de la Iglesia. Bauer consultó las fuentes de la Secretaría de Marina del Archivo General de Simancas y publicó la relación de árboles y especies que halló en el "Estado General de los Bosques de Corregimientos del Principado de Cataluña en que se hallan árboles de todos géneros, buenos para la fábrica de navíos". En este documento que reproduce el ingeniero alemán se mencionan 993.416 árboles repartidos entre pinos $(82 \%)$ robles $(11 \%)$ hayas $(4 \%)$ abetos $(2 \%)$ encinas $(1 \%)$ y en cantidades menores chopos, álamos blancos, álamos negros, y fresnos ${ }^{23}$. Estas cifras destacan por mostrar unos valores muy bajos dejando a los bosques de pinos de Tortosa como los más poblados del Principado aunque con importantes rasos. Un hecho que refleja Bauer cuando el concejo de Tortosa se quejaba en 1777 de la autorización concedida para efectuar la corta de 2.600 pinos con destino a la fortificación de la plaza de Orán, dado el mal estado de sus bosques, aunque finalmente fue autorizada. Por último, Bauer también incluye el Estado del arbolado en la provincia de Marina de San Feliu de Guíxols, correspondiente al año de 1783 y que también se custodia en Simancas, que refleja un aumento considerable de árboles, sobre todo de aquellos denominados como nuevos.

Todos estos datos ofrecidos por Bauer en sus distintos trabajos son reproducidos, comparados y analizados en otra obra colectiva titulada La transformación histórica del paisaje forestal en Cataluña, editada por el Ministerio de Medio Ambiente. Este interesante trabajo es, sin duda, la mejor aportación que hemos encontrado sobre la evolución de los bosques de Cataluña a lo largo de la historia. En el capítulo titulado La cuestión de los Montes en la Edad Moderna, los autores analizan el siglo de la Ilustración explicando los recursos forestales de Cataluña durante el siglo XVIII para lo que emplean distintas fuentes que van

22. Bauer, E., Los Montes de España en la Historia, Madrid, 1980.

23. Estas cifras también aparecen en Bauer, E., "Los bosques españoles. Evolución forestal de España en el Marco Europeo". Domingo Santos, J.; Calzado Carretero A. Los montes y su historia: una perspectiva política, social y económica. Huelva, 2016. p. 45. 
desde las visitas practicadas a mediados de siglo hasta los diarios de los viajeros contemporáneos ${ }^{24}$.

Con un enfoque distinto y desde la óptica de la historia naval contamos con otra obra de altura: El Arsenal de Cartagena en el siglo XVIII, un interesante trabajo de María Teresa Pérez-Crespo Muñoz que estudia la construcción y el funcionamiento de las diferentes actividades del arsenal como la maestranza, los diques, muelles, gradas, fábricas, almacenes, etc. analizando muchos de los problemas que se sucedieron en torno a la edificación del complejo fabril así como de todo lo relacionado con la construcción naval. En el capítulo dedicado a las maderas, Pérez-Crespo incluye a los Montes de Cataluña dentro de las regiones de aprovisionamiento de robles y pinos empleando como novedad para la investigación documentos del Archivo Naval del Arsenal de Cartagena. ${ }^{25}$

Para finalizar este breve recorrido historiográfico no podemos olvidar las conclusiones a las que llegaron los contemporáneos, especialmente en lo referente a la deforestación de los bosques catalanes a lo largo del siglo XVIII. Entre los textos que hacen referencia a este hecho destaca el Discurso de la Junta Económica de Comerç sobre la agricultura, comercio e industria del Principado de Cataluña de 1780, que ofrece una visión deplorable de los bosques catalanes señalando las causas del desastre. ${ }^{26}$ En la misma línea, pocos años después, en 1787 Manuel Barba exponía de manera crítica desde la Academia de Ciencias y Artes de Barcelona cuáles habían sido los resultados de la aplicación de la Ordenanza de montes de Marina de $1748 .^{27}$ Este autor, considerado uno de los más destacados agraristas catalanes, defendía la iniciativa privada para garantizar la producción forestal y la venta o arriendo de los montes concejiles para permitir un aprovechamiento más rentable. Una medida que ya había sido propuesta en Castilla por el Marqués de Piedrabuena, destacado miembro de la Academia de Agricultura que envío una larga Representación al Consejo de Castilla donde incluía entre sus argumentos la privatización de la tierra como medida para contribuir a la mejora de la producción forestal. ${ }^{28}$

También, por la misma fecha Antonio Ponz ${ }^{29}$ y Ricardo Zamora ${ }^{30}$ ofrecían a través de sus viajes una visión particular sobre el estado de los Montes de Ca-

24. Casals Costa, V.; Pardo Navarro, F.; Xalabarder Aulet, M.; Postigo Mijarra, J.M., La transformación histórica del paisaje forestal en Cataluña. Ministerio de Medio Ambiente.

25. Pérez-Crespo Muñoz M.T., El Arsenal de Cartagena en el siglo XVIII. Madrid, 1992

26. Junta de Comerç de Barcelona, Discurso sobre la agricultura, comercio e industria del Principado de Cataluña (1780), Barcelona, 1995.

27. Barba, M., "Observaciones generales sobre el estado actual de la agricultura en Cataluña (1787)". Argemí D’Abadal., Agricultura e Ilustración, Ministerio de Agricultura, Pesca y Alimentación, Madrid 1998, pp. 441-449.

28. Urteaga, L., La Tierra Esquilmada. Las ideas sobre la conservación de la naturaleza en la cultura española del siglo XVIII. Madrid, 1987, p. 141.

29. Ponz, A., Viage de España, en que se da noticia de las cosas más apreciables, y dignas de saberse, que hay en ella, Viuda de Ibarra, (1772-1794), Madrid 1972, t. XIV, pp. 91-98.

30. Zamora, F. de., Diario de los viajes hechos en Cataluña (1785-1790). Barcelona, 1973. 
taluña a finales del siglo XVIII exponiendo los motivos de su regresión. En este sentido Zamora justificaba como principal causa del deterioro de los montes la injerencia del Estado Absolutista por medio de la Real Hacienda y la Marina. Un argumento propio de la época que repite Jovellanos en su Ley Agraria y también Martín Fernández de Navarrete cuando hace referencia a los montes de Segura de la Sierra administrados durante la misma época también por la Marina. Todos siguen las corrientes del liberalismo económico del momento llegando a la conclusión de que lo mejor sería que los montes pasasen a propiedad privada ${ }^{31}$.

Sin embargo todos ellos olvidan los métodos empleados por los vecinos y autoridades municipales para protestar por la injerencia del Estado Absolutista con la aplicación de las ordenanzas de Montes que privaron a los naturales del país de la gestión y el aprovechamiento de dichos bosques. Unas protestas que incluían los incendios forestales que se unían a las talas indiscriminadas perpetradas por habitantes de la región. Estos hechos, repetidos en toda la geografía nacional, provocaron un notable deterioro de las masas forestales en Cataluña tal y como podemos comprobar en la abundante documentación al respecto ${ }^{32}$.

Las roturaciones, el consumo de leña y carbón para las industrias, la acción de los rebaños o los incendios fueron causas más que suficientes para reducir la superficie forestal en Cataluña aunque los contemporáneos no dudaron en acusar denodadamente a la construcción naval como el principal azote de los bosques del Principado culpando al régimen impuesto por las Ordenanzas de 1748.

\section{Metodología y fuentes primarias para la investigación}

Como hemos visto al principio, desde el siglo XVIII a nuestros días han venido publicándose una serie de trabajos que con mayor o menor profundidad han estudiado los montes de Cataluña y su proyección naval durante aquella centuria subrayando la singularidad de unos bosques a veces alejados del mar pero curiosamente dependientes de la Marina. Aunque la mayoría de estudios se limitan a ciertas comarcas o bien tan solo se trata de meras referencias también se han producido rigurosos trabajos de investigación que, con notable acierto han analizado la explotación forestal y el régimen administrativo de los Montes de Cataluña. Así pues, una investigación exhaustiva debe partir de estas obras para obtener las primeras conclusiones y una base documental con la que reconstruir la historia de

31. Fernández de Navarrete, M., Expediente sobre el Régimen y Administración de los Montes de Segura de la Sierra y su Provincia. Madrid, 1825.

32. Por ejemplo en 1788 cuando el alcalde de Alfara en la jurisdicción de los montes de Tortosa denunció las talas indiscriminadas provocadas por pastores y labradores (ANC, Libro de Acuerdos de la Junta Económica: Junta celebrada el 2 de septiembre de 1788) . 
las Provincias Marítimas del Principado de Cataluña durante el siglo XVIII junto con la aportación, revisión, observación, comparación y análisis de las fuentes primarias.

Una vez definido el tema a tratar, en una primera fase, debe emplearse el método histórico contextualizando el espacio temporal, delimitando el ámbito de la investigación, identificando las fuentes y formulando una serie de hipótesis.

En cuanto a las fuentes primarias, estas se encuentran dispersas debido a la existencia de distintos archivos inconexos entre sí y alejados geográficamente, con el inconveniente que tan solo una mínima parte de los fondos se encuentran digitalizados por lo que se debe acudir a ellos en persona. Una vez en el archivo hay que seleccionar una serie de contenidos que aparecerán clasificados, en el mejor de los casos, o simplemente referenciados con los epígrafes "montes y plantíos", "maderas para la construcción naval" y "arsenales", contenidos que se incluyen, según las fuentes documentales, en manuscritos y cartografía. Para realizar esta selección debemos tener presente que, relacionado con nuestro tema de estudio, nos vamos a encontrar documentación que haga referencia a montes, bosques, terrenos desarbolados y de matorral, visitas de montes, marcado de maderas, organización de la Administración forestal, superficies y vías de extracción de maderas y productos forestales, arrastre y desembosque, formación de tinglados y secaderos, estados de existencias de maderas y masas forestales, descripciones botánicas, tarifas de maderas, piezas de maderas según las especies forestales, piezas de maderas para arquitectura naval, enfermedades de la madera, consumos de madera para la construcción naval, pinadas, diseños de construcción naval, asientos de maderas, asientos para la fabricación de buques, astilleros, carenas, recorridas, calafateado, reglamentos de recepción de maderas así como referencias de carácter histórico, cultural y social sobre la época a través de ordenanzas, instrucciones, resoluciones, comunicaciones, etc.

Una vez recogidos, valorados e interpretados los datos obtenidos en la investigación archivística validaremos las hipótesis iniciales y ofreceremos conclusiones aplicando el método científico comprobando las evidencias obtenidas. Todo ello con el fin de edificar una historia total, verdadera cuestión de Estado para la monarquía borbónica del siglo XVIII que se aleja de la historia local y regional que hasta el momento ha planteado la historiografía pues, en primer lugar se debe poner orden a lo ya escrito en cuanto al régimen administrativo, el proceso de la explotación forestal o las resistencias locales, revisando nuevas fuentes que nos puedan aclarar todos estos hechos. Para ello, junto al método histórico, pondremos en práctica el método experimental comparando los datos obtenidos en relación al número de piezas, al volumen de madera conducida desde los Montes de Cataluña a los arsenales, la fecha de llegada y los trabajos de construcción y carenado con el fin de relacionar e 
identificar las naves para las que fueron destinadas las maderas. De esta manera cumpliremos con uno de nuestros objetivos conectando la corta y traslado de las maderas con el proceso de construcción naval, métodos, carenas, recorridas, etc. que se dieron en los arsenales de la Marina, especialmente Cartagena, dentro del contexto de la España de la Ilustración, de la reconstrucción de su Armada y de la política de equilibrio internacional y defensa de los territorios de ultramar emprendida por los Borbones del siglo de las Luces.

Junto al método cualitativo deben emplearse también técnicas cuantitativas para traducir los fenómenos en cifras que midan variables como el número de árboles seleccionados, la cantidad de piezas de cada pinada o las carenas y recorridas efectuadas en los arsenales durante cada etapa, lo que responderá a otras cuestiones en torno al impacto ambiental, a la localización del destino de las maderas o a valorar, igualmente, la importancia cuantitativa de las maderas de Cataluña en los navíos, fragatas y embarcaciones menores de la Armada Española del siglo XVIII. Esta metodología puede completarse con la aportación de otras ciencias auxiliares como la arqueología cuyo método puede ser de utilidad para el estudio de los restos de maderas que aún se conservan en algunos lugares y que pueden proceder de la explotación forestal de los bosques de Cataluña durante el siglo XVIII.

Para la puesta en práctica de la metodología que hemos detallado debemos aplicar este método en primer lugar sobre los trabajos ya escritos. Así pues, una vez estudiadas, valoradas y analizadas críticamente las fuentes secundarias a las que venimos haciendo referencia más aquellas que se añaden en la bibliografía final, pasamos al proceso fundamental e imprescindible de búsqueda, análisis e interpretación de las fuentes primarias. Para ello en primer lugar debemos de partir de los fondos del Archivo General de Simancas (Valladolid) concretamente a la Sección Secretaría de Marina que incluye un total de 749 legajos y 75 libros lo que hace un conjunto de 824 unidades, numeradas correlativamente, clasificadas en 29 grupos o series que suelen comenzar en 1720 y terminar en 1783 . Dentro de este fondo de Marina, de legajos de un tamaño con frecuencia desmesurado pero bien ordenados e identificados, con cartelas originales hechas con gran esmero, son de obligada consulta para la investigación de nuestro tema la sección de Montes y sus incidencias. En total 28 legajos que hacen referencia a nombramientos y comisiones de personal (celadores, visitadores, escribanos, delineantes). Este fondo ha sido el más utilizado por los investigadores que se han interesado por el estudio las Provincias Marítimas o la evolución del paisaje. Mucho más empleado que la sección de Arsenales que a menudo ha pasado desapercibida y que, sin embargo, ofrece una interesante información sobre el destino de las maderas de Cataluña. Nos interesan para esta sección las unidades comprendidas entre 1720 hasta 1783, algo más de medio centenar de legajos que nos informan sobre construcción de buques, carenas y recorridas, edificación de arsenales, 
diques, auxilios a embarcaciones, acopios, etc., donde a veces nos podemos encontrar gruesos expedientes bajo el título maderas de Cataluña, maderas de Tortosa o maderas de los Alfaques.

Una vez concluida nuestra visita a Simancas debemos acudir al Archivo General de Marina, instalado en el Palacio de Don Álvaro de Bazán en el Viso del Marqués (Ciudad Real), que custodia los legajos Ilegados de la Secretaría de Marina desde 1784 siguiendo la ordenación vista en Simancas. Así podemos continuar nuestra labor de manera ordenada revisando la sección de Arsenales donde, entre sus 762 legajos, encontraremos información referente a la construcción y carena de los buques, diques y almacenes, así como a la habilitación de los mismos para expediciones diversas. Destaca por su interés los diez primeros legajos de la subsección de "Generalidad", dos legajos de "Registros de Todas las Zonas" que nos adelantan algunos datos a modo de resumen y sobre todo "Maderas" donde encontramos referencias a los montes de Cataluña entre sus 21 legajos correspondientes a los años comprendidos entre 1761 a 1805 donde las maderas de Cataluña comparten espacio con las de Irati, Asturias, Burgos, Santander, Sierra de Segura y Alcaraz o Andalucía.

Para completar nuestra investigación debemos acudir Madrid donde existe abundante documentación complementaria en su Archivo Naval. Allí se custodian muchos manuscritos de los siglos XVIII y XIX referentes tanto a la edificación de los arsenales como a la construcción naval propiamente dicha (Colección Sanz de Barutell, Colección Vargas Ponce, etc.) donde hallamos referencias a nuestro tema en algunos manuscritos de las secciones de Montes y Maderas además de alguna documentación cartográfica de notable importancia. En primer lugar podemos hallar manuscritos referentes a la explotación forestal de los Montes de Cataluña antes del siglo XVIII lo que nos servirá para elaborar los antecedentes. Respecto a esta documentación encontramos en la Colección Navarrete la Memoria sobre la saca de madera en los montes Pirineos para fabricar galeras de 1560. De la Colección Vargas Ponce, anteriores al siglo XVIII tenemos del año 1668 Recibo y conducción de maderas en los montes del Principado de Cataluña; Maderas que se cortaron en los montes de Cataluña para las Atarazanas de Barcelona y que se hacen galeras con madera cortada en Gibraltar; y Cortas de maderas en los montes del Principado de Cataluña. De 1689 encontramos Cortas de madera en los Montes de Cataluña; Relación de la madera que se debe cortar en los bosques de Cataluña. De 1690 Relación de maderas que se deben cortar en los montes de Cataluña; y de 1694 Cortas de madera en los montes de Cataluña. Ya en el siglo XVIII y dentro de la misma colección encontramos en el año 1718 Construcción de una cubierta para poner árboles que Ileguen de Tortosa; Dos cartas de 1751 del Marqués de la Ensenada a Francisco Barrero para que de los montes de Cataluña y Andalucía se conduzcan maderas a Cartagena para la construcción de seis navíos y sobre Labra de madera y cortas de madera en los montes de Cataluña. De 1782 encontramos Visitas a los montes de Cataluña; de 1784 Suspensión de cortas de maderas de roble hasta 
nueva providencia, excepto la de roble de Cataluña y la de álamo negro y pino de curbería y ligazones menores del Reino de Murcia; de 1786 la Abolición del Reglamento de 1772 sobre los precios de los árboles en el Principado de Cataluña; del mismo año Tasación y compra de los montes destinados para carbón de la fábrica de Muga en Cataluña; de 1787 Señalamiento de los árboles en los montes de Cataluña; Establecimiento de la Ordenanza de Marina en Puigcerdá, Talarn, Valle de Arán y Cervera; y una carta de Antonio Valdés sobre la conservación y fomento de los montes de Cataluña; por último de 1791 Contrata para el arrastre de maderas de pino abeto y melis royal de los montes de Cervera y Talarn a los ríos Segre y Noguera Pallaresa.

En el Museo Naval de Madrid, también podemos consultar la edición original del "Diccionario demostrativo con la configuración y anatomía de toda la arquitectura naval moderna", más conocido como el Álbum del Marqués de la Victoria. Un libro de enormes dimensiones escrito por Juan José Navarro entre 1719 y $1759^{33}$. Entre las 133 láminas de este magnífico estudio sobre la construcción naval destaca la número 22 (de $127 \mathrm{~cm}$ x $46 \mathrm{~cm}$ ), firmada en 1740 como Jefe de la Escuadra y dedicada al Infante Don Felipe de Borbón y que se titula: "Plano Topographico, con la Explicación de todos los lugares de Cataluña, Aragón, Navarra y Castilla donde se cultiva y recoge Cañamo y la cantidad anual que hazen los Hornos de Alquitran, Brea y Betun. La Descripsión de los Rios Ebro, Zinca, Segre, Aragon, Galligo y Esca, Con todos los Montes de Bosques inmediatos a estos Rios propios para la construcción de Navios". En el mapa aparecen dibujados los cursos fluviales mencionados con indicación de ciudades y la situación de los bosques que se localizan con una letra mayúscula. Al mapa le rodean varios textos que permiten valorar la situación de los recursos forestales en una parte de Cataluña para mayor interés de la Armada. Sin duda esta fuente gráfica nos puede servir de mucha ayuda para descubrir la riqueza forestal de los bosques catalanes a raíz de las visitas practicadas por el capitán de fragata Juan Valdés en 1739 así como el interés despertado en la Armada por sus maderas.

Una vez completada la investigación en Madrid es inexcusable la visita al Arsenal de Cartagena, sede del Departamento del mismo nombre, a donde fueron destinadas la mayor parte de las maderas de Cataluña. En su archivo, instalado en el interior del complejo naval, se conservan interesantes datos en torno a los montes de Cataluña y su relación con la Marina tal y como se desprende de la información que contienen las secciones de Reales Órdenes y los Libros de Acuerdos de la Junta Económica. La primera sección abarca desde 1726 y contiene todas las disposiciones promulgadas como Departamento Marítimo. La segunda es la más interesante pues incluye una ingente cantidad de temas con

33. Una tirada de 100 ejemplares fue publicada bajo el título Álbum del Marqués de la Victoria, por Lunwerg Editores en Madrid, 1995. 
una cronología que se inicia en 1772 y cuyo contenido es difícil de sintetizar, aunque ya hemos encontrado numerosas referencias a las maderas de Cataluña. Junto a esta sección merecen interés algunos papeles sobre comisionados y comisiones para abastecimiento de maderas. Asimismo, también es importante investigar el tema en la serie denominada "Correspondencia con el exterior" en la que existe alguna documentación administrativa y de cuenta y razón entre la "Contaduría Principal del Departamento Marítimo de Cartagena" y los ministros e intendentes del Principado, desde 1769.

Siguiendo con la búsqueda de fuentes primarias, no podemos olvidar el Archivo de la Corona de Aragón con sede en Barcelona, donde en la unidad Arxiu del Reial Patrimonio de Catalunya podemos descubrir datos en la sección de Procesos. Allí aparecen documentos relativos a asientos, conducción y ventas de maderas entre 1720 y 1799 y dos interesantes documentos referidos a diligencias practicadas para la venta de pinos para arboladuras de navíos ${ }^{34}$ y maderas para la construcción de galeras en Barcelona ${ }^{35}$.

Para concluir con la búsqueda de fuentes primarias sobre nuestro tema, señalaremos que existe alguna documentación residual sobre el mismo en otros centros como la Biblioteca Nacional de Madrid donde encontramos sobre todo alguna cartografía de interés. También el Archivo Histórico Nacional donde hallamos algunos pleitos en las Secciones de Órdenes Militares y Consejos.

Una vez hecha la descripción y secuenciada la serie pasamos al análisis e interpretación de la documentación acumulada y su comparación con los datos y conclusiones ofrecidas en las fuentes secundarias donde también hemos ordenado los datos de manera parecida.

A partir de aquí la información la ordenaremos de forma cuantitativa (número de piezas transportadas, año, arsenal de destino, tipo de obra: construcción, carena, recorrida...) y cualitativa comparando y conectando datos, identificando embarcaciones y respondiendo las preguntas inicialmente planteadas.

Una vez recogido el fruto de las investigaciones de otros historiadores, con la ayuda de nuevas fuentes documentales y con la revisión de las ya analizadas hasta ahora, estamos en condiciones de ofrecer una propuesta científica para renovar, explicar, aclarar discusiones, explorar nuevas líneas de investigación y establecer definitivamente una relación entre las maderas de Cataluña y la Marina de la Ilustración. Sin embargo, una investigación con tales pretensiones excede de los límites espaciales de un artículo científico por lo que nos

34. Archivo de la Corona de Aragón (en adelante ACA) Real Patrimonio, BGRP, Procesos, $1721, n^{\circ}$ 5, D: Diligencias practicadas para la venta de maderas de pino para la arboladura de navíos, que están en la playa de Sant Feliu de Guixols.

35. ACA, Real Patrimonio, BGRP, Procesos, 1720, $\mathrm{n}^{\circ} 4, \mathrm{Bc}$ : Diligencias practicadas para el asiento del aparejo de maderas cortadas en el Vallès que se han de cuadrear para la fabricación de galeras en Barcelona. 
limitaremos a presentar una introducción sobre las maderas de Cataluña y la Marina de la llustración dejando para más adelante un proyecto de mayores dimensiones.

\section{Antecedentes. La explotación forestal y construcción naval catalana hasta el siglo XVIII}

Desde la época medieval, el Principado de Cataluña estuvo íntimamente ligado al devenir del Mediterráneo y en él jugaron un papel clave las Atarazanas de Barcelona. La existencia de esta factoría se remonta a 1243 durante el reinado de Jaime I. A partir de entonces sucesivas fases irán desarrollando este complejo fabril hasta convertirlo en el principal astillero de la Corona de Aragón especializándose en la construcción de galeras. Las materias primas empleadas para esta primigenia industria naval procedían habitualmente de los bosques catalanes de donde llegaban maderas y arboladuras que quedaban custodiadas dentro del recinto de las atarazanas que incluía almacenes de pertrechos.

El volumen de maderas cortadas y transportadas en la Corona de Aragón entre los siglos XIII y XIV debió ser considerable pues durante este periodo, la armada aragonesa del Mediterráneo llegó a contar con ochenta galeras. Por esta razón a partir del siglo XV, los montes cercanos a Barcelona, más accesibles a las Atarazanas, comenzaron a declinar lo que provocó que se adoptaran medidas para evitar la importación de tablazón y arboladuras para así preservar las masas boscosas para las necesidades navales del reino.

A comienzos del siglo XVI las fuerzas navales del Mediterráneo no superaban las doce unidades por lo que se dieron instrucciones para la reactivación de las Atarazanas barcelonesas. En este sentido, tanto el virrey del Principado, en 1525, como las Cortes de Monzón de 1552 así como las de 1564, insistieron en la prohibición de sacar maderas fuera de Cataluña salvo aquellas destinadas para buques reales. Unas medidas que reflejaban, por un lado, la autonomía de las instituciones catalanas dentro de la Monarquía Hispánica de los Austrias y por otro el alejamiento de las tentaciones de los asentistas de hacer negocio en el extranjero.

Durante el siglo XVII los bosques del principado, especialmente los de Tortosa, sufrieron las consecuencias de la expulsión de los moriscos que fueron embarcados con destino al exilio en galeras reales y fletes privados que fueron construidos y habilitados empleando buena parte de los árboles que habían sido preservados durante la centuria precedente. ${ }^{36}$

Ante el abuso y abandono de los bosques del Principado, el Capitán General de Cataluña, Miguel de los Santos San Pedro promulgó en 1627 las Ordinacions

36. Martínez González, A. J., Las Superintendencias... pp. 125-149. 
de montes. Un documento que en su introducción dibuja un panorama desolador de los bosques del Principado. Posteriormente y a lo largo de diecisiete capítulos aborda la cuestión de las licencias para efectuar talas regulando las cortas de la Marina e imponiendo penas a los que incumplieran una normativa que volvía a insistir en la prohibición de las exportaciones de madera.

Pocos años después, la Guerra dels Segadors (1640-1659), en paralelo con la guerra franco-española iniciada en 1636, provocó graves efectos en los bosques catalanes, especialmente los de Poblet, que fueron arrasados por los franceses. Tras este episodio, en la segunda mitad del siglo XVII la actividad de las Atarazanas de Barcelona quedó estancada y apenas se practicaron cortas de maderas en los montes catalanes mientras se buscaron árboles en otras regiones más meridionales para la reparación de las escasas y obsoletas galeras que aún formaban parte de la Armada del Mediterráneo.

\section{Maderas de Cataluña durante la primera mitad del siglo XVIII. La Ordenanza de montes de 1748 y sus implicaciones en Cataluña}

Cataluña fue el principal bastión de los partidarios de la causa austracista durante la Guerra de Sucesión. Tras su derrota militar fue ocupada por el ejército borbónico. Barcelona fue sitiada y parcialmente destruida en 1714 y las instituciones catalanas fueron suprimidas. En 1716 fue promulgado el Decreto de Nueva Planta, base de la nueva legislación catalana cuyas instituciones quedaron sometidas al poder del rey siguiendo el modelo de centralismo borbónico de origen francés. Esta nueva normativa afectó en el terreno económico, fiscal y también forestal.

La Guerra de Sucesión supuso también la drástica reducción del poderío naval español. Un hecho verdaderamente preocupante para una monarquía que seguía siendo universal. Fue entonces cuando comenzaron a tomarse las primeras reformas tendentes a aumentar el número de buques de guerra con el fin de, al menos, garantizar las comunicaciones con las colonias de ultramar.

La construcción naval de buques de la Armada en España tuvo su edad de oro en el siglo XVIII, en la época de la Ilustración. Esta expansión tuvo su origen en el momento en que la monarquía de los Borbones se supo heredera, nada más comenzar la centuria, de un vasto imperio ultramarino que había de conservar desde el mar por lo que la defensa de las costas de ambos hemisferios, el control de las rutas oceánicas y la protección del comercio debían ser vitales para la supervivencia del Estado ante las injerencias y amenazas de las potencias europeas, especialmente de Inglaterra. Para ello había que crear una potente y eficaz flota de buques de guerra capaz de proteger las orillas del Atlántico, el Pacífico y el Mediterráneo y, al menos, servir como fuerza disuasoria ante las ofensivas británicas.

Este diagnóstico fue asumido inicialmente por José Patiño, el primero de los grandes ministros reformistas considerado el fundador de la Armada Española del 
siglo XVIII, quien tuvo en el mar su principal campo de actuación. Desde la Secretaría de Marina e Indias, Hacienda y Guerra, y finalmente la de Estado, Patiño asumió el reto de la reconstrucción de la Marina Española promoviendo en primer lugar la creación de los arsenales que la Corona necesitaba para tal fin, concibiéndolos como complejos navales integrales, dotándolos de astilleros permanentes y estructurándolos como centros de mantenimiento y reparación de embarcaciones. Para esta ambiciosa política era necesaria la creación de astilleros modernos y para tal misión, en 1724, se designaron las ciudades de Ferrol, Cartagena y Cádiz para ubicar los departamentos marítimos desde donde se debían estructurar las distintas funciones y estrategias administrativas y militares de la Marina Española.

Pero para llevar a cabo esta ambiciosa política era necesario hacer acopio de un recurso natural indispensable: la madera, materia prima hasta entonces insustituible para la construcción de barcos. A finales de la década de 1730 se realizaron varias visitas a los montes de Segura de la Sierra, Cataluña, Aragón y Navarra por el capitán de fragata Juan Valdés para hacer una primera valoración de la riqueza maderable que podría disponer la Marina para sus arsenales. Este hecho tuvo su origen en 1737 cuando el intendente Francisco de Varas le confirió al capitán Juan Valdés y Castro una instrucción para el reconocimiento de los pinos que se encuentren en los montes de Cataluña para actos de arboladura y tablazón. En 1739, tras haber realizado los trabajos encomendados, Valdés redactó Diario, especulación y conocimiento hecho por el Capitán de Fragata Don Juan de Valdés y Castro en el Principado de Cataluña, Reyno de Aragón, y de Navarra, de los Ríos, Riveras, Fabricas de Jarcia, Alquitranes, Betunes, Arboles, y cosechas de Cáñamos de cada Pueblo. Este Diario es un minucioso manuscrito de 34 páginas que, además de enumerar datos geográficos, técnicos, medidas, cifras de arbolado, calidades y otros detalles, recoge una serie de comentarios relativos a aspectos jurídicos sobre la utilidad para la Marina de terrenos privados, vecinales o eclesiásticos.

Adjunto al Diario, Valdés emitió un informe en el que habló de la necesidad de compensar las cortas de árboles ubicados en terrenos particulares mediante el pago a sus propietarios con una cantidad que debería ser justa, aspecto que pareció preocuparle especialmente, ya que en sus escritos incidió mucho sobre el resarcimiento por los perjuicios que se podrían causar a los propietarios por las talas que practicara la Marina, un hecho que confirmó Antonio Gallego de Montemayor, quien había acompañado a Valdés en su viaje, que emitió otro informe complementario en el que manifestaba que había estado intentando inculcar a los naturales de cada región sobre la necesidad de compatibilizar sus prácticas forestales consuetudinarias con las necesidades del real servicio naval, un hecho que provocaría graves enfrentamientos entre los intereses locales y los de la Armada tal y como comprobó personalmente en los montes de Cataluña. ${ }^{37}$

37. Martínez González, A. J., "La elaboración de la Ordenanza de Montes de Marina, de 31 de enero de 1748, base de la política oceánica de la monarquía española durante el siglo 
El informe de Juan Valdés, que se incluye en una de las láminas del Álbum del Marqués de la Victoria, concluye alabando las maderas de Cataluña y su empleabilidad para usos de la Armada.

Poco después, en 1745 se ordenó una visita general a todos los bosques maderables por oficiales de la Armada para evaluar el estado de los recursos forestales en los montes próximos a las costas, levantando planos, determinando el número de árboles y especies para, una vez remitidos los resultados, valorar la riqueza forestal del país. Fue entonces cuando se promulgó la Ordenanza de 31 de enero de 1748 para la conservación y aumento de los montes de Marina en las provincias y distritos que se expresan $(. . .)^{38}$ donde se incluían los montes y bosques realengos y propios de los pueblos correspondientes a las provincias de Tuy, Santiago, Coruña y Betanzos en Galicia, los del Principado de Asturias, Cantabria, Señorío de Vizcaya, Guipuzcoa y Reino de Navarra en el norte, dependientes del Departamento Marítimo de Ferrol. El Departamento de Cádiz tomó bajo su jurisdicción los montes de Andalucía y Segura de la Sierra, cuya vertiente daba a los ríos Guadalquivir y Guadalimar. Por último, en el Departamento de Cartagena, quedaron adscritos los Montes de Segura, en este caso los correspondientes a la vertiente oriental que daban al río del mismo nombre, los del Reino de Granada, Murcia, Almería, Valencia y los del Principado de Cataluña. En este último territorio se incluían los montes de Tortosa y los términos de Llobregat, Vallés, Selva de Girona, Ampurdam hasta el río Ter, Montseni, Hostal-Rich, Sansaloni, Balgorgina, y los demás montes de las riberas de los ríos Segre, Cinca y Llobregat en cuyos terrenos -según la ordenanza- (...) se crían robles, alcornoques, encinas, nogales, alisos, fresnos, álamos y otros árboles de útil aplicación a la construcción de los bajeles y uso de su artillería.

Los capítulos 76, 77 y 78 de las Ordenanzas de montes de Marina están dedicados a Cataluña, cuyo ámbito de aplicación y actividades relacionadas regulan. Especial atención presta a los montes de Tortosa, a los que están dedicados los capítulos 77 y 78 . El 77 manda "se conserven y aumenten" los pinares cuya madera sea útil para la construcción de arboladuras y "fábrica de Betunes", para lo cual debe repoblarse los calveros resultado de talas anteriores (lo que es síntoma del mal estado de los mismos), y que para los aprovechamientos futuros de los pinos para las finalidades antes señaladas se manden "personas inteligentes y prácticas". Por último, el capítulo 78, regula la fabricación de pez y alquitrán por parte de los vecinos de Tortosa,

XVIII." Anuario de Estudios Americanos, 71,2, julio-diciembre 2014, p. 583.

38. ANC: Ordenanza General de Montes de 1748. Ejemplar Impreso en Cartagena por Pedro Ximénez. También en Novísima Recopilación de las leyes de España. Tomo III. Libros VI y VII: Ley XXIII. pp. 530-543. 
una actividad que, tradicionalmente, se les había permitido pero que había sido objeto de restricciones en las Ordinacions de 1627. Con las ordenanzas de 1748 recuperaban este oficio aunque su continuidad y desempeño estuvo sujeta a licencia. ${ }^{39}$

En Cataluña las Ordenanzas fueron hechas públicas por el intendente general, José de Contamina, el 20 de febrero de 1748, en cuyo documento incorporó un preámbulo y un epílogo. El preámbulo iba dirigido a los subdelegados y "demás personas á quienes toca", para que cumplieran puntualmente lo que en las ordenanzas se prescribía, mientras que en el epílogo señalaba que iba a elegir visitadores para reconocer, numerar y describir las existencias y calidad de los árboles de los diferentes territorios, debiendo advertir a las Justicias y regidores de los pueblos de que serían castigados si no atendían las nuevas ordenanzas.

En 1751 el marqués de la Ensenada dictó una nueva Instrucción que en parte ampliaba y modificaba las citadas Ordenanzas. En el punto segundo, se señalaba la confección de una relación de los pueblos afectados por la jurisdicción de la Marina en materia de montes. La relación incluye 1.088 pueblos y lugares, distribuidos entre las provincias marítimas de Mataró, Sant Feliu de Guixols, Tarragona, Tortosa y de los Corregimientos de Gernoa, Vic y Manresa.

A partir de entonces la monarquía intervino en los bosques a través de los inspectores de Marina. En Prades se limitó la presencia de cabras para preservar la riqueza forestal. Además, los pastores no podían portar hachas ni herramientas cortantes. Por último, se obligaba a limpiar el sotobosque y podar de noviembre a febrero.

Como resultado de esta Ordenanza se hicieron nuevas visitas a los montes con objeto de conocer sus existencias dando lugar al "Estado General de los Bosques de Corregimientos del Principado de Cataluña en que se hallan árboles de todos géneros, buenos para la fábrica de navíos" que ofrece unos valores relativamente bajos siendo los bosques de pinos de Tortosa los más abundantes. ${ }^{40}$

Así pues, a mediados del siglo XVIII los bosques de Cataluña contribuyeron con maderas y otros productos forestales a la construcción y carenado de los buques de la Armada coincidiendo con el inicio de actividad del arsenal de Cartagena. Sin embargo la explotación forestal de los bosques de Cataluña con destino a la construcción naval venía de atrás, al menos desde finales del siglo anterior. De este modo los robles de Girona y Barcelona y especialmente los pinos de Tortosa y el Delta del Ebro habían surtido a los astilleros locales de Sant Feliu de Guixols

39. ANC: Ordenanza General de Montes de 1748. Para el estudio de las Ordenanzas de 1748 ver González A. J., "La elaboración de la Ordenanza de Montes de Marina, de 31 de enero de 1748, base de la política oceánica de la monarquía española durante el siglo XVIII". Anuario de Estudios Americanos, 2014, vol. 71, nº 2, pp. 571-602.

40. Casals Costa, V.; Pardo Navarro, F.; Xalabarder Aulet, M.; Postigo Mijarra, J.M., La transformación histórica... pp. 158-163. 
donde se construyeron los navíos Real San Felipe, de 80 cañones, el San Bartolomé, de 66, conocido también como Cambí, y Nuestra señora de Montserrat, apodado El Cathalán de 70 cañones. ${ }^{41}$ Para su fábrica se emplearon las maderas de los robles de Gerona y Barcelona, y los pinos de Tortosa y el Delta del Ebro, que habían sido tradicionalmente utilizados por los buques de la Marina tanto para tablazón como para arboladuras. Para este último empleo se habían usado desde finales del siglo XVII hasta al menos mediados del XVIII cuando fueron sustituidos por las arboladuras rusas. En 1697 se hizo un asiento general para arboladura, tablazón y betunes procedentes de Tortosa con destino a los tres departamentos de Marina de Ferrol, Cádiz y Cartagena. Un asiento que fue renovado en distintas ocasiones permaneciendo en vigor hasta 1733 con algunas variaciones. ${ }^{42} \mathrm{Sin}$ embargo, a mediados de siglo comenzaron a lanzarse las primeras críticas en torno a la calidad de las arboladuras de Tortosa que había que renovar con demasiada frecuencia. Fue entonces cuando los pinos del Báltico y de Rusia comenzaron a suplir a los de Tortosa que dejaron de ser habituales para perchas, no así para tablazón puesto que los arsenales siguieron consumiendo periódicamente los pinos de esta comarca no solo para la construcción naval sino incluso para la edificación de las instalaciones de los propios arsenales como ocurrió en 1745 cuando se pidieron maderas de los Alfaques para la reparación de las naves de arboladura y otras dependencias del arsenal de La Carraca. ${ }^{43}$

\section{La explotación forestal durante la segunda mitad del siglo XVIII. El transporte de las maderas catalanas y su empleo en los arsenales}

En cuanto a la llegada al arsenal, las maderas catalanas lo hicieron a través de las vías fluviales del Principado. Un método que se venía practicando desde la época medieval para el abastecimiento maderero de las Atarazanas de Barcelona donde ya fueron empleados con frecuencia árboles procedentes de los Pirineos aprovechando las corrientes de los ríos Ara y Cinca. ${ }^{44}$

La madera de los montes Pirineos, tanto roble como pino coral melis, era extraída desde sus altos valles por una serie de pequeños ríos y recogida luego

41. Sobre los astilleros de Sant Feliu de Gixols ver Hamelink, M.P.; De Pablo, P.D.L.F., La Reial Fàbrica de Vaixells de Sant Feliu de Guíxols (1715-1721), Sant Feliu de Guíxols: Ayuntamiento de Sant Feliu de Guíxols, 2009. Hubo también un proyecto para instalar un arsenal en Barcelona a mediados de siglo tal y como estudia Hamelink, M.P.; De Pablo, P., De la Fuente, L.F., Tarcha, C. Un proyecto de arsenal para la Barceloneta (1743) An Arsenal Project in La Barceloneta (1743). Vegueta: Anuario de la Facultad de Geografía e Historia, 14, 2014.

42. Merino Navarro, J.P., La Armada española... pp. 187, 258, 326.

43. AGS, Marina, leg. 313: Relación de las maderas de los Alfaques de Tortosa que se necesitan para techar dos naves de arboladura, el tinglado del obrador y almacén..., Rubalcaba, Cádiz, 2 de febrero de 1745.

44. Pallaruelo, S. ob. cit. p. 42. 
en primera instancia por dos caudalosos afluentes del Ebro: el río Aragón, en la región forestal de Navarra y Aragón occidental y el Segre-Cinca en la región de Aragón oriental y Cataluña. El sistema de transporte más utilizado era el de las almadías, en Navarra, navata en Aragón y rai en Cataluña. Se trataba de una especia de balsa construida con los propios troncos objeto del transporte que a veces solía emplearse también como barca para conducir personas y mercancías, tal y como describió el viajero Francisco Zamora en 1788:

yo estuve dentro de estos tramos de vigas, los cuales gobiernan con un remo delante y otro detras, y sobre ellos ponen unos banquillos en que se lleva a la tierra baja trigo, vino, aceite y muchas gentes van en ellos a Lérida y Tortosa. ${ }^{45}$

Dado que en los tramos más altos de los ríos no podían formarse almadías por ser su curso muy estrecho, de fuerte pendiente y poblado de escollos, se recurría a la conducción de los troncos en piezas sueltas, ayudándose de un gancho o ganxa, tal y como sucedía en el sur con las conducciones por el Guadalquivir y Segura desde la Provincia Marítima de Segura de la Sierra. Esta operación previa era conocida como la barranquedada. Cuando el río tenía suficiente caudal els raiers o almadieros, construían un pequeño rai o xabec que conducían desde la orilla y en el que transportaban los pertrechos necesarios para los operarios de la maderada. Al igual que se hacía en el Guadalquivir, Segura, Alto Tajo, Cabriel y Turia, también en los ríos catalanes construían adobos para salvar obstáculos.

Los puntos donde se construían las almadías se llamaban ataderos y en ellos se apilaban las maderas que habían de ser transportadas. Las operaciones comenzaban en el mes de octubre, aprovechando la crecida del caudal que le proporcionaba el deshielo de las nieves de invierno y las lluvias de primavera. Antes de iniciar la marcha, cada primavera se hacía navegar una pequeña almadía de inspección para que explorara el tramo por donde tenía que bajar la madera y fuera anotando los pasos difíciles y limpiando el cauce de obstáculos como vegetación de ribera, árboles encajados e incluso piedras, haciendo además algunos adobos con troncos en los pasos complicados para que las almadías pudieran bajar más rápidamente.

En la parte oriental de Aragón y en Cataluña la madera era bajada desde los valles pirenaicos por el río Segre y sus afluentes Cinca, Noguera Ribagorzana y Noguera Pallaresa. Según la visita de Juan Valdés de 1739, para las arboladuras era idóneos los abetos que crecían en la cabecera del Noguera Ribagorzana en el Vall de Boí, mientras que en el vecino valle del Noguera Pallaresa los pinos silvestres y laricios de los montes de Boumort, eran aptos para perchas

45. Zamora, F. Diario de los viajes hechos en Cataluña (1785-1790). Barcelona 1973, Edición e introducción a cargo de Ramon Boixareu. p. 207. 
y tablonería. Otros bosques catalanes explotados por la Armada fueron los de Ribalera de Trívia en Pallars Sobirà y los de la cuenca alta del Segre. ${ }^{46}$ Por último no podemos olvidar la comarca de Tortosa, rica en maderas como el pino rojo tortosino o pi roig tortosi que no es otro que el pinus sylsvestris o coral melis, muy apreciado para arboladuras. Esta especie se cría en las umbrías de las vecinas sierras de Montsant y de Beseit con salida directa al Ebro, río en el que confluían todas las maderas para navegar durante varios meses más hasta llegar precisamente a Tortosa, ciudad situada en una posición estratégica, junto al margen izquierda del Ebro y a escasa distancia de su desembocadura, donde se hallaba el embarcadero marítimo de los Alfaques desde donde las maderas eran embarcadas para ser conducidas definitivamente a los arsenales. ${ }^{47}$ No obstante las maderas de Cataluña con destino a los arsenales de Marina no solo partieron de los Alfaques de Tortosa pues también lo hicieron de las playas de Sant Feliu de Guixols, Rosas, Mataró o Blanes. ${ }^{48}$

En 1752 las maderas de Cataluña llegaron al arsenal de Ferrol por vía marítima, haciendo escala en Cádiz donde también quedaron algunos palos. ${ }^{49} \mathrm{Al}$ gran arsenal gallego volverían a enviarse maderas de aquel Principado, al menos en 1771,1779 y más tarde en 1818 cuando el Capitán General de Cataluña dispuso que se hiciera uso de algunas perchas menudas de Cataluña destinadas a Ferrol. ${ }^{50}$ En cuanto a la Carraca parece que después de 1752 debieron de llegar pocas maderas de aquel Principado pues en febrero de 1758, Juan Gerbaut aseguró que hacía mucho tiempo que en aquel arsenal no había pinos de Tortosa y todas los que había hasta ese momento se habían empleado en los baos y la tablonería del navío España botado en La Carraca en 1757. ${ }^{51}$

Otro de los arsenales que se nutriría de los robles y pinos de Cataluña fue el de Mahón, en Menorca, a donde llegaron partidas entre los años 1785 y 1789. Sin embargo sería el arsenal de Cartagena el que más aprovecharía las maderas de Cataluña tanto los pinos de Tortosa como el roble de los Pirineos, al menos desde 1752 a 1791, periodo donde prácticamente llegaron de manera ininterrumpida para emplearse en la construcción de navíos, fragatas o jabeques pero también para los trabajos de carena. ${ }^{52}$

La explotación forestal de los bosques catalanes en beneficio de la Marina coincide con el impulso de actividad que a mediados del siglo XVIII tuvo el

46. Piqueras Haba, J.; Sanchis Deusa, M.C., La conducción fluvial... pp. 68-81.

47. Piqueras Haba, J.; Sanchis Deusa, M.C., La conducción fluvial ... pp. 83-84.

48. ANC, Caja, 2731. Junta del Departamento Libros de Acuerdos, Tomo 9: Junta celebrada el 12 de enero de 1782.

49. AGMAB, Arsenales, leg. 3759: 24 de agosto de 1752.

50. AGMAB, Arsenales, leg. 3760: 10 de marzo de 1818.

51. AGS, Marina, leg. 328: Gerbaut a Arriaga, Cádiz, 22 de febrero de 1758.

52. AGMAB, Arsenales, leg. 3759, 3760; ANC, Caja, 2729. Junta del Departamento Libros de Acuerdos. 
arsenal de Cartagena. Hasta allí las maderas de Cataluña Ilegaron mediante el sistema de asiento por medio de asentistas como los Mena o los Gil y Mester, que se encargarían de proporcionar maderas de Cataluña y Valencia a precios que ascendían desde los 52 reales de vellón por codo cúbico entre 1749 y 1752, fecha a la que Ilegan a Cartagena 55.994 codos cúbicos en 12.372 piezas de construcción. ${ }^{53}$ Quince años después los precios se dispararon hasta los 80 y 106 reales, un encarecimiento provocado por el alza del precio de los fletes. ${ }^{54}$ Un hecho que se refleja especialmente cuando las maderas eran conducidas en las urcas del rey. ${ }^{55}$

A partir de la década de los setenta para los acopios de madera del Principado se destinaron para la explotación directa comisionados de la propia Armada como Ignacio Gallego, Roque Bien, Antonio Conte, Manuel Bernia, Luis Hevia o Plácido Correa. ${ }^{56}$ Un método que era compartido con el tradicional sistema de asiento continuado por nombres como Damián Llull. ${ }^{57}$

Durante el último tercio y hasta finales de siglo los bosques catalanes comenzaron a resentirse por culpa de las demandas madereras de la incipiente industria catalana y por el aumento demográfico, sectores que compitieron con la construcción naval incidiendo negativamente en la salud de los bosques del Principado. Este hecho prácticamente coincide con la decisión que tomó la Junta de Cartagena cuando en 1793 dio por finalizadas las cortas de pinos en Cataluña de la siguiente manera:

La madera de pino que viene a este arsenal anualmente por los asentistas del ramo es muy suficiente para todas sus atenciones y propone que sería conveniente que se retiren los comisionados a su costa de la Real Hacienda en los montes de Segura de la Sierra, Caravaca y Cataluña luego que hayan concluido el aguadero y remesas de las piezas que tengan cortadas. ${ }^{58}$

De este modo las maderas de Cataluña dejaron de abastecer al arsenal de Cartagena después de casi cincuenta años de suministro ininterrumpido. Aun así, durante los primeros años del siglo XIX tenemos constancia de que las cortas en Cataluña continuaron, al menos en el condado de Enril. También en 1811 se pidió al gobernador de Peñíscola que extrajera maderas de Torto-

53. Merino Navarro, J.P., La Armada española ... p. 314.

54. Merino Navarro, J.P., La Armada española... p. 212.

55. ANC, IMVa, Leg 1, carpeta 3: Juan Gerbaut a Arriaga, Cádiz, 27 de julio de 1759.

56. ANC Caja $175, \mathrm{n}^{\circ} 3$, Comisionados en las provincias al acopio de géneros y maderas.

57. ANC, Caja, 2731. Junta del Departamento Libros de Acuerdos, Tomo 7.

58. ANC, Caja, 2734, Libros de Acuerdos de la Junta Económica, Tomo 16: Junta celebrada el 10 de octubre de 1792; AGMAB, Arsenales, leg: 3795: El marqués de Casa Tilly a Antonio Valdés, Cartagena, 13 de octubre de 1792. 
sa para el arsenal de Cartagena, ${ }^{59}$ un hecho aislado, sin duda, que coincide con la crisis de la construcción naval española y el ocaso de la Marina de la Ilustración.

\section{Bibliografía}

Aranda y Antón, G., Los bosques flotantes; historia de un roble del siglo XVIII. Madrid, 1990.

Aranda y Antón, G., "Relaciones documentales de los bosques y montes marítimos peninsulares en los archivos históricos españoles durante el siglo XVIII y comienzo del XIX". Revista Ecología, 17, 2003, pp. 359-379.

Aranda y Antón, G., "Los bosques y los montes españoles en los archivos históricos de la Marina Española". Revista de Historia Naval, 21, pp. 13-48.

Aranda y Antón, G., La carpintería y la industria naval en el siglo XVIII. Instituto de Historia y Cultura Naval (Cuadernos monográficos del I. H. C. N., n 33), Madrid, 1999.

Alberola Romá, A., Mas Galván, C. y Die Maculet, R. (Eds.), Actas del Congreso Jorge Juan Santacilia en la España de la Ilustración. Alacant, 2015.

Argemí D’Abadal, L., Agricultura e Ilustración, Ministerio de Agricultura, Pesca y Alimentación. Madrid, 1988.

Bauer Manderscheid, E., Los Montes de España en la Historia. Madrid, 1980.

Belenguer, E., Dantí, J. y Gual, V. (Eds.), Els béns comunals a la Catalunya moderna. Dalmau Editor, Barcelona, 1998.

Belenguer, E., Dantí, J. y Gual, V. (Eds.), La comunitat pagesa catalana a través dels documents (1349-1871). Rafael Dalmau, Barcelona, 1999.

Casado Rubanal, D., La Marina Ilustrada. Sueño y ambición de la España del siglo XVIII. Madrid, 2009.

Casado Soto, J.L., Los barcos españoles del siglo XVI y la Gran Armada de 1588. Madrid, 1988.

Casals Costa, V., Pardo Navarro, F., Xalabarder Aulet, M. y Postigo Mijarra, J.M., La transformación histórica del paisaje forestal en Cataluña. Ministerio de Medio Ambiente, Madrid, 2005.

Cayuela, J., Trafalgar. Hombres y naves entre dos épocas. Barcelona, 2004.

Cervera Pery, J., La marina de la Ilustración. Madrid, 1986.

Cobo de Guzmán y Lechuga, J., Estudio sobre las Ordenanzas de Montes de 1748. Jaén, 1989.

59. AGMAB, Arsenales, leg. 3760: 16 de agosto de 1811. 
Cruz Aguilar, E., La destrucción de los montes (claves histórico-jurídicas). Madrid, 1990.

De la Fuente, P. y Hamelink, M.P., La Reial Fàbrica de Vaixells de Sant Feliu de Guíxols (1715-1721). Ayuntamiento de Sant Feliu de Guíxols, Sant Feliu de Guíxols, 2009.

De la Fuente, P., Hamelink, M.P. y Taracha, C., "Un proyecto de arsenal para la Barceloneta (1743)/An Arsenal Project in La Barceloneta (1743)". Vegueta: Anuario de la Facultad de Geografía e Historia, 14, 2014, pp. 229-241.

De la Fuente, P. y Hamelink, M.P., "Fusta dels boscos de Requesens per a la construcció de navilis de I'orde de Malta (1702-1704)". Annals de I'Institut d'Estudis Empordanesos, 46, 2015, pp. 413-428.

Domingo Dantos, J. y Calzado Carretero, A., Los montes y su historia: una perspectiva politica, social y económica. Huelva, 2016.

Fumanal i Pagès, M. À., Galimany Bustos, E. y López Prat, M., "El rètol de Fígols... o la marina de Carles III al cor del Pirineu", Tribuna $d^{\prime}$ arqueologia, 2006, 2007, pp. 255-271.

Grau Josep M. T., y Puig i Tàrrech, R., L'Aprofitament del bosc a l'època moderna: la Conca de Barberà, s. XVIII, Rafael Dalmau, Barcelona, 1990.

Juan-García Aguado, J. M. de, José Romero Fernández de Landa. Un ingeniero de Marina en el siglo XVIII. Universidad de A Coruña, A Coruña, 1998.

López, P.B., Les Visions del bosc a la Catalunya de la I/ lustració. Societat Catalana d'Història de la Ciència i de la Tècnica, Filial de l'Institut d'Estudis Catalans, 2008.

Maluquer de Motes, J., "L'explotació del bosq i el transport de la fusta (els raiers)". L'Avenc, 34, pp. 36-43.

Martínez González, A.J., "Masas forestales para las Armadas: las áreas jurisdiccionales de montes y plantíos (siglos XVI-XVIII)". Naveg@mérica, 14, 2015. Disponible en: http://hdl.handle.net/10201/44088.

Merino Navarro, J.P., "El arsenal Ilustrado del Mediterráneo español". Áreas, 1, 1981, pp. 39-52.

Merino Navarro, J.P., La Armada española en el siglo XVIII. Fundación Universitaria Española, Madrid, 1981.

Pérez-Crespo Muñoz, M.T., El Arsenal de Cartagena en el siglo XVIII. Editorial Naval, Madrid, 1992.

Piqueras Haba, J. y Sanchis Deusa, M.C., La conducción fluvial de maderas en España. Arcis Ediciones, Godella (Valencia), 2015.

Piqueras Haba, J. y Sanchis Deusa, M.C., "El transporte fluvial de madera en España: geografía histórica". Cuadernos de Geografía, 2001, pp. 127-162.

Ponz, A., Viage de España, en que se da noticia de las cosas más apreciables, y dignas de saberse, que hay en ella (1772-1794). Madrid, 1972. 
Portet, À., "Els raiers: el transport fluvial de la fusta del Pirineu a la Mediterrània". Plecs d'història local, 62, 1996, pp. 968-971.

Quintero González, J., Jarcias y lonas. La Renovación de la Armada en la Bahía de Cádiz 1717-1777. Cádiz, 2003.

Quintero González, J., La Carraca, el primer arsenal ilustrado español (17171776). Madrid, 2004.

Ribas J. M., "La Indústria de la construcció naval catalana (1750-1850): una visió a llarg termini". Drassana: revista del Museu Marítim, 2, 1994, pp. 34-39.

Ricart y Giralt, J., "El siglo de oro de la marina velera de construcción catalana", en Memorias de la Real Academia de Ciencias y Artes de Barcelona, 18, 1924, pp. 177-201.

Roda Alcayud, C., "Fuentes para el estudio de la historia naval: los fondos del Archivo General Intermedio de la Armada en Cartagena.", Nicolás Marín, M. E. y González Martínez, C. (Coords.), Ayeres en discusión: Temas clave de Historia Contemporánea hoy. Universidad de Murcia, Murcia, 2008.

Rodríguez, E., "L'Explotació forestal al Pallars durant el segle XVIII: els raiers". Drassana: revista del Museu Marítim, 4, 1995, pp. 16-21.

Ruiz García, V., De Segura a Trafalgar, Torredonjimeno, 2010.

Ruiz García, V., La Provincia Marítima de Segura y la Marina de la Ilustración. La contribución de las maderas de Segura de la Sierra a la construcción naval del siglo XVIII. Instituto de Estudios Giennenses-Diputación Provincial de Jaén, Jaén, 2019.

Urteaga, L., La Tierra Esquilmada. Las ideas sobre la conservación de la naturaleza en la cultura española del siglo XVIII. Madrid, 1987.

Urteaga, L., "La política forestal del reformismo borbónico", Lucena, M., (Ed.), El bosque ilustrado. Estudios sobre la política forestal española en América. Instituto Nacional para la Conservación de la Naturaleza, 1991, pp. 17-43.

Uztariz, G., Theorica, y Practica de Comercio y Marina, en diferentes discursos, y calificados explemplares que, con especificas providencias, se procuran adaptar a la Monarquia Española, para su prompta restauración, beneficio universal, y mayor fortaleza contra los émulos de la Real Corona. Madrid, 1757.

Valdez-Bubnov, I., Poder naval y modernización del Estado: política de construcción naval española (siglos XVI-XVIII). México, 2011.

Vilar, P., Catalunya dins l'Espanya Moderna, , 4 vols., Edicions 62, Barcelona, 1968. Versión castellana, Vilar, P., Cataluña en la España Moderna, 3 vols., Crítica, Barcelona, 1987.

Zamora, F., Diario de los viajes hechos en Cataluña (1785-1790). Barcelona, 1973. 